\title{
Letter to the Editor: Cutaneous diphtheria in a migrant from an endemic country in east Africa, Austria May 2014
}

S Huhulescu ${ }^{1}$, S Hirk ${ }^{1}$, V Zeinzinger ${ }^{1}$, P Hasenberger ${ }^{1}$, H Skvara² ${ }^{2}$ R Müllegger², F Allerberger (Franz.Allerberger@ages.at)ㄹ, A Indra ${ }^{1}$

1. Austrian Agency for Health and Food Safety (AGES), Institute for Hygiene and medical Microbiology, Diphtheria-Reference Laboratory, Vienna, Austria

2. Landesklinikum Wiener Neustadt, Department of Dermatology, Wiener Neustadt, Austria

Citation style for this article:

Huhulescu S, Hirk S, Zeinzinger V, Hasenberger P, Skvara H, Müllegger R, Allerberger F, Indra A. Letter to the Editor: Cutaneous diphtheria in a migrant from an endemic country in east Africa, Austria May 2014. Euro Surveill. 2014;19(26):pii=20845. Available online: http://www.eurosurveillance.org/ViewArticle. aspx?Articleld $=20845$

Article submitted on 27 June 2014 / published on 03 July 2014

\section{To the editor:}

In their recent article, Both et al. pointed out that the unavailability of diphtheria antitoxin (DAT) constitutes a risk for patients presenting with diphtheria across Europe and may hamper diphtheria diagnostics [1].

In Austria, DAT is also no longer available since 2011. However, 21 years after the last documented Austrian case of diphtheria due to toxigenic Corynebacterium diphtheriae, an east African teenager was diagnosed with cutaneous diphtheria in May 2014. He had been hospitalised on 25 April, after arriving in Austria via Italy, for secondary infected skin wounds with impetigo appearance mainly on extremities and treated with intravenous ampicillin/sulbactam (3 g i.e. $2 \mathrm{~g}$ ampicillin/1 g sulbactam every 8 hours for 7 days). On admission, he had a total white blood cell count of $13.7 \mathrm{x}$ $10^{9} / \mathrm{L}$ (norm: 3.8-9.8 $\times 10^{9} / \mathrm{L}$ ), neutrophils $10.33 \times 10^{9}$ /L (norm: 1.5-7.0 $\times 10^{9} / \mathrm{L}$ ), and a C-reactive protein of $2.73 \mathrm{mg} / \mathrm{dL}$ (norm: $<0.5 \mathrm{mg} / \mathrm{dL}$ ). The wound swab taken from a leg ulcer on 25 April yielded C. diphtheriae, Staphylococcus aureus and Streptococcus dysgalactiae equisimilis (Lancefield group C). Microbiological diagnosis was hampered by delays in specimen transport and reporting of results; the Diphtheria-Reference Laboratory received the isolate on 19 May.

The World Health Organization (WHO) Global Reference Centre for Diphtheria and Streptococcal Infections at Public Health England (PHE), London, United Kingdom, confirmed the isolate as toxigenic $C$. diphtheriae biovar mitis. Minimum inhibitory concentration for benzylpenicillin was $0.25 \mathrm{mg} / \mathrm{L}$ determined by Epsilometer (E) test on a blood agar plate. The European Committee on Antimicrobial Susceptibility Testing (EUCAST) have no species specific breakpoints for $C$. diphtheriae, but the strain can be categorised as resistant to benzylpenicillin according the EUCAST recommendations for Corynebacterium sp.-related breakpoints [2]. Penicillinresistance is not unusual among tropical $C$. diphtheriae strains, rendering benzylpenicillin ineffective for treatment [3].

Both et al.'s statement, that supply and access to DAT is insufficient in Europe, has been confirmed by our experience in Austria. We were unable to procure DAT for a patient with toxin-producing $C$. ulcerans infection in May 2013 and are still without any stock of DAT. The interim guidelines of PHE require that antitoxin should be given if ulcers in cases of cutaneous diphtheria are larger than $2 \mathrm{~cm}^{2}$, as was the case in our patient [4].

It has long been recognised that $C$. diphtheriae can cause clinical skin infections characterised by chronic non-healing ulcers with a dirty greyish membrane and often superinfected by Staphylococcus aureus and haemolytic streptococci [5]. Skin carriage of C. diphtheriae can act as a silent reservoir for the organism, and it has been found that person-to-person spread from infected skin sites is even more efficient than from the respiratory tract in causing classical respiratory diphtheria [6]. The carriage of tox-positive lysogenic $C$. diphtheriae also poses a risk that nontoxigenic strains, which are regularly found in Austrian residents, could become lysogenised by introduction of such a beta-phage-bearing strain.

In our case, when the Diphtheria Reference Laboratory alerted the treating clinicians and public health authorities on 23 May about the diagnosis of toxigenic $C$. diphtheriae, the patient had already left the hospital on their own initiative and could not be contacted hereafter. We would like to point out that travel and migration to and from countries where diphtheria is still endemic may pose a risk for re-emergence of the disease and therefore public health authorities are well advised to ensure availability of DAT as a WHO essential medicine. 


\section{Acknowledgments}

The authors would like to thank the WHO Reference Centre for Diphtheria and Streptococcal Infections, Public Health England, London, United Kingdom for performing confirmatory tests.

\section{Conflict of interest}

None declared.

\section{Authors' contributions}

$\mathrm{SH}, \mathrm{SH}, \mathrm{AF}$ and $\mathrm{Al}$ wrote the draft manuscript. $\mathrm{VZ}$ and $\mathrm{PH}$ performed bacteriological work. HS and RM provided clinical data. All authors corrected and approved the final version.

\section{References}

1. Both L, White J, Mandal S, Efstratiou A. Access to diphtheria antitoxin for therapy and diagnostics . Euro Surveill. 2014;19(24): $\mathrm{pii}=20830$.

2. European Committee on Antimicrobial Susceptibility Testing (EUCAST). Breakpoint tables for interpretation of MICs and zone diameters; version 4.0, 1 Jan 2014. Växjö: EUCAST; 2014. Available from: http://www.eucast.org/ fileadmin/src/media/PDFs/EUCAST_files/Breakpoint_tables/ Breakpoint table $v$ 4.0.pdf

3. 3. May ML, McDougall RJ, Robson JM. Corynebacterium diphtheriae and the returned tropical traveler. J Travel Med. 2014;21(1):39-44. http://dx.doi.org/10.1111/jtm.12074

4. Public Helath England (PHE). Diphtheria Guidelines Working Group. Public health control and management of diphtheria (in England and Wales): Interim Guidelines. April 2014. London: PHE; 2014. Available from: http://www.hpa.org.uk/webc/ HPAwebFile/HPAweb_C/1317141014343

5. Jakovljev A, Steinbakk M, Mengshoel AT, Sagvik E, BrüggerSynnes P, Sakshaug T, Rønning K, Blystad H, Bergh K. Imported toxigenic cutaneous diphtheria in a young male returning from Mozambique to Norway, March 2014. Euro Surveill. 2014;19(24): $\mathrm{pii}=20835$

6. Koopman JS, Campbell J. The role of cutaneous diphtheria infections in a diphtheria epidemic. J Infect Dis. 1975;131(3):239-44. 